\title{
Profile of Crohn's Disease Patients Who Underwent Anorectal Examination under Anesthesia
}

\author{
Alexandre Lopes de Carvalho ${ }^{1,2}$ Natalie Fernanda Baqueiro Sena1(0) \\ Jamile Caramello Ortins Sampaio ${ }^{10}$ Aline de Oliveira Trajano ${ }^{10}$ Lina Maria Goes de Codes ${ }^{10}$ \\ Flávia de Castro Ribeiro Fidelis ${ }^{1 \oplus}$ Rogerio Souza Medrado de Alcantara ${ }^{30}$ Marcelo da Silva Barreto ${ }^{4}$
}

1 Serviço de Coloproctologia, Hospital Universitário Professor Edgard

Santos, Universidade Federal da Bahia, Salvador, Bahia, Brazil

Address for correspondence Alexandre Lopes de Carvalho, Medical

2 Serviço de Coloproctologia, Hospital da Bahia, Salvador, Bahia, Brazil Doctor (MD), Rua Várzea de Santo Antônio 316, Residencial Versailles,

3 Serviço de Cirurgia Geral, Hospital Ana Nery, Salvador, Bahia, Brazil

${ }^{4}$ Serviço de Cirurgia Geral, Hospital Santo Antônio, Obras

Assistenciais Irmã Dulce, Salvador, Bahia, Brazil

J Coloproctol 2021;41(3):275-280.

\begin{abstract}
Introduction Crohn's disease (CD) is an inflammatory bowel disease, and in $\sim 30 \%$ of cases it is associated with perianal manifestations. To identify the extent of the damage and to implement an appropriate treatment, anorectal examination under anesthesia (EUA) is fundamental.

Objective To describe the profile of patients who underwent anorectal EUA in university and private hospitals in the state of Bahia, Brazil.

Methodology A retrospective, descriptive study with 46 patients who underwent anorectal EUA between March, 2016 and November, 2019.

Results A total of 62 anorectal EUAs were performed in 46 patients. With an average age of 36.8 years, the female gender was predominant (52.2\%) among these patients. Anal fistulas were the most frequent findings $(83.8 \%)$, and in most cases they were treated with a seton placement (69.4\%). The main recommended surgical indication

Keywords

- Anorectal EUA

- Crohn's disease

- anal fistulas

- infliximab

- seton was a proper evaluation and identification of perianal disease, followed by drainage of the abscess and therefore immunobiological therapy (59.6\%).

Conclusion In the present study, the profile of $C D$ patients was similar to those found in the literature, with a high rate of complex anal fistulas. Additional studies are still necessary to further comprehend and treat this particular and debilitating manifestation of the disease.
\end{abstract}

\section{Introduction}

Crohn's disease (CD) is a chronic, autoimmune inflammatory bowel disease. Its main characteristic is a transmural inflam- mation, which can affect any layer of the gastrointestinal tract. Its etiology is still unknown, but it can be predominantly inflammatory, structuring, or fistulizing. Cases of $C D$ have been growing significantly around the world. ${ }^{1,2}$ received

August 21, 2020

accepted

January 15, 2021

published online

July 19, 2021
DOI https://doi.org/

10.1055/s-0041-1730015.

ISSN 2237-9363.

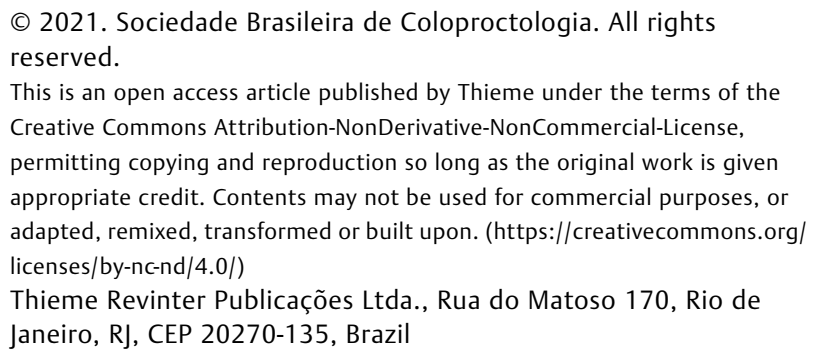

(C) 2021. Sociedade Brasileira de Coloproctologia. All rights reserved.

This is an open access article published by Thieme under the terms of the Creative Commons Attribution-NonDerivative-NonCommercial-License, permitting copying and reproduction so long as the original work is given appropriate credit. Contents may not be used for commercial purposes, or adapted, remixed, transformed or built upon. (https://creativecommons.org/ licenses/by-nc-nd/4.0/)

Thieme Revinter Publicações Ltda., Rua do Matoso 170, Rio de Janeiro, RJ, CEP 20270-135, Brazil 
Penner et al. were the first researchers to describe perianal manifestations, in $1938 .^{3}$ They are frequently detected in CD patients with abscesses, fistulas and other findings. ${ }^{4}$ Fistulas develop in $\sim 30 \%$ of these patients. ${ }^{5}$ Combined with CD, fistulas are responsible for a high morbidity rate and low quality of life (QoL), besides the risk of fecal incontinence due to a compromised anal sphincter complex, a condition caused by inflammatory response and inadvertent damage during anal exploration or surgical procedures. ${ }^{6,7}$

Anal fistulas are a more serious and debilitating phenotype of $C D$. The involvement of the perianal region is frequently associated with intense pain, making the anorectal exam unbearable for several patients. Although endoanal ultrasound (EAUS) and magnetic resonance imaging (MRI) in the evaluation of perianal region have shown high accuracy, they do not replace examination under anesthesia (EUA), which allows diagnosis and treatment simultaneously. ${ }^{6-8}$ The treatment of fistulas in CD patients remains a controversial subject, and may be one of the most challenging aspects in patient care.

The present study describes the profile of $C D$ patients who underwent EUA in the Department of Coloproctology of the Hospital Universitário Professor Edgard Santos (HUPES, in the Portuguese acronym) at the Universidade Federal da Bahia (UFBA, in the Portuguese acronym) and at the Hospital da Bahia.

\section{Methods}

A retrospective, descriptive study analyzed 46 patients who underwent 62 EUAs. All procedures were performed between March, 2016 and November, 2019: 46 of them in the Department of Coloproctology of the HUPES, and 16 in the Hospital da Bahia. Our data were collected from medical records including $\mathrm{CD}$ patients with compromised perianal region submitted to EUA.
Our analysis included the following variables: age, gender, disease duration, extraintestinal manifestations, drug treatment prior to EUA, smoking, surgery indication, surgery background, type of anesthesia, clinical presentation and localization of the disease, and use of antibiotic prophylaxis. We also report findings and procedures performed within the EUA.

The present study was approved by the HUPES Committee (CAAE: 16852619.0.0000.0049) and meets the institution requirements, as well as the principles of the Declaration of Helsinki.

Data processing and analysis were performed with the aid of the R Program software, version 3.6.1 ( $R$ Foundation, Vienna, Austria).

At a level of significance of 5\%, categorical variables were compared using the Fisher Exact test, being presented in absolute numbers and percentages, and quantitative variables were compared using the Mann-Whitney U nonparametric test.

\section{Results}

A total of 62 EUAs were performed in $46 \mathrm{CD}$ patients. With an average age of 36.8 years old (ranging from 7 to 64 years old), these patients were predominantly females (52.2\%). The average time between the diagnosis and the procedure was 6.3 years. The prevalence of smokers and former smokers was of $2.2 \%$ for each category. Some patients were submitted to previous surgeries in different stages of the disease. Four patients were submitted to previous seton placement in other facilities, three patients to anal stenosis dilation, three patients to fistula tract curettage, four patients to right hemicolectomy, one patient to Hartmann procedure, and two patients to a total colectomy with ileostomy.

Out of 46 patients, 8 (17.4\%) presented extraintestinal manifestation (EIM), as described in - Figure 1. Among them, two presented more than one EIM.

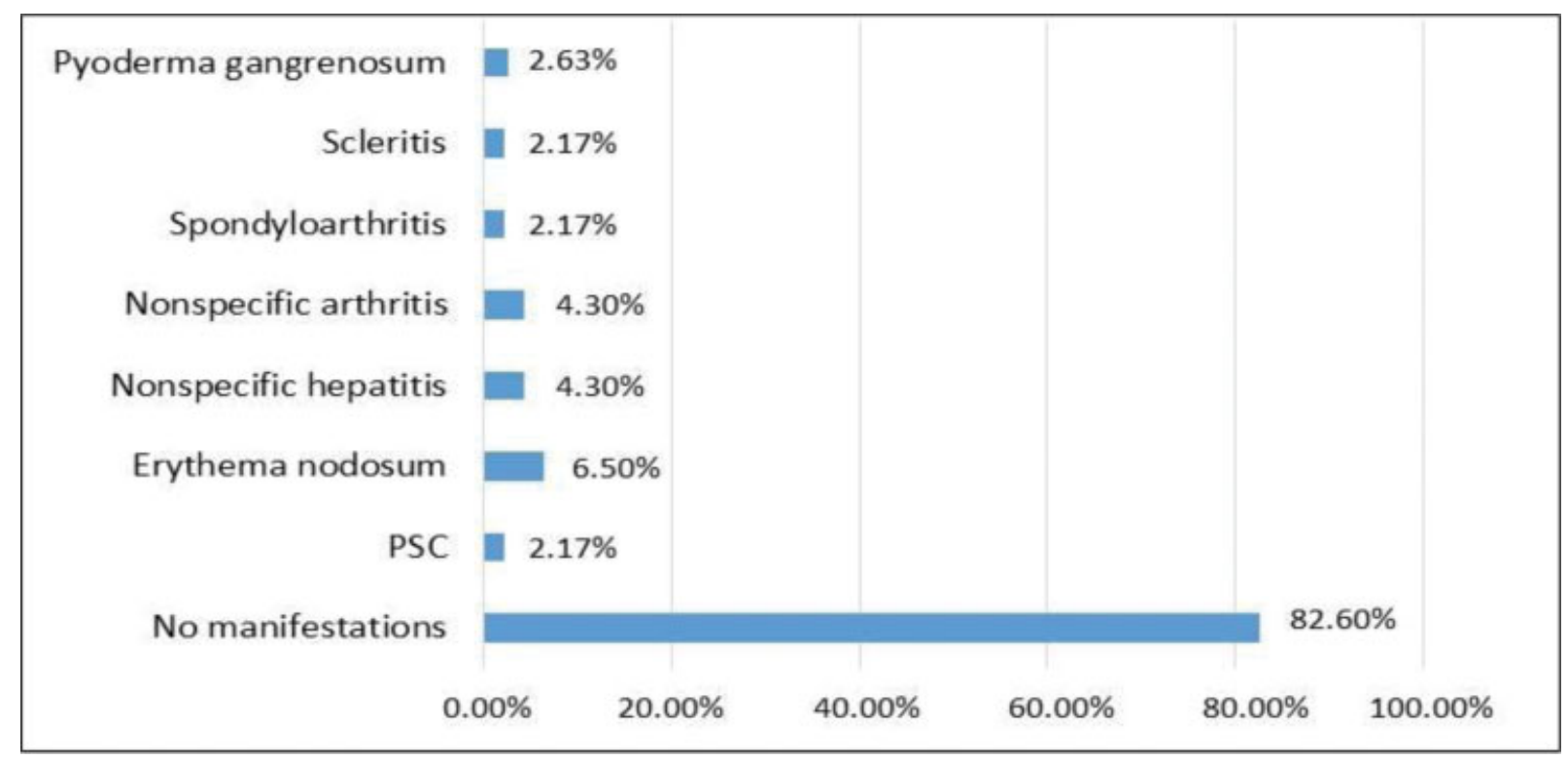

Fig. 1 Extraintestinal manifestations. 
Table 1 Drug treatment prior to EUA

\begin{tabular}{|l|l|}
\hline Drug treatment prior to EUA & $\boldsymbol{n}=62$ \\
\hline No medication & $11(17.7 \%)$ \\
\hline Azathioprine + Infliximab & $11(17.7 \%)$ \\
\hline Azathioprine & $10(16.1 \%)$ \\
\hline Infliximab & $6(9.7 \%)$ \\
\hline Mesalamine & $5(8.0 \%)$ \\
\hline Sulfasalazine & $3(4.8 \%)$ \\
\hline Azathioprine + Adalimumab & $3(4.8 \%)$ \\
\hline Adalimumab & $2(3.2 \%)$ \\
\hline Mesalamine + Azathioprine + Prednisone & $2(3.2 \%)$ \\
\hline Mesalamine + Azathioprine & $2(3.2 \%)$ \\
\hline Mesalamine + Corticoid & $2(3.2 \%)$ \\
\hline Prednisone & $1(1.6 \%)$ \\
\hline Sulfasalazine + Infliximab & $1(1.6 \%)$ \\
\hline Certolizumab & $1(1.6 \%)$ \\
\hline
\end{tabular}

Abbreviation: EUA, examination under anesthesia.

- Table 1 specifies the drugs used on the patients shortly before the EUA. A noticeable number of patients was not medicated when they underwent the EUA (17.7\%). The most common scheme performed was a combination of infliximab (IFX) with azathioprine (17.7\%). Other frequent schemes also included infliximab (9.7\%) or oral mesalamine (8.0\%). Due to the presence of abscess and new fistulas, patients under immunobiological therapy had to stop their treatment prior to the EUA, which justified the procedure.

The Montreal Classification for CD was applied to 46 patients: 36 (78.3\%) were categorized as B1p (nonstricturing, nonpenetrating, with perianal disease modifier), 5 (10.8\%) as B2p (stricturing with perianal disease modifier), and 5 (10.8\%) as B3p (penetrating with perianal disease modifier). Four patients $(8 \%)$ presented both penetrating and stricturing behavior.

The main surgical intervention recommendation (59.6\%) was proper evaluation and identification of perianal disease, followed by identification and drainage of fistulas before moving to immunobiological therapy. Interventions were also recommended when new fistulas appeared due to drainage of pus (17.7\%), seton displacement (4.8\%), anorectal pain $(11.2 \%)$, and anorectal abscess $(6.4 \%)$.

In most cases, the anesthetic choice for EUAs was spinal anesthesia and sedation (88.7\%), followed by nerve block with sedation (13.5\%). The lithotomy position was the choice for all the EUAs, with no bowel preparation in any patient.

The description of intraoperative findings and of the most commonly performed procedures is represented in - Table 2 . The most common findings were anal fistulas (83.8\%), subdivided in complex (78.8\%) and simple (21.2\%) according to the American Gastroenterological Association (AGA) classification. ${ }^{9}$ The prevalence of rectovaginal fistulas was of $21 \%$. The most common treatment was seton placement, performed
Table 2 Intraoperative findings and performed procedures

\begin{tabular}{|l|l|}
\hline Intraoperative findings & $n=62$ \\
\hline Anal fistulas & $52(83.8 \%)$ \\
\hline Rectovaginal fistulas & $13(21 \%)$ \\
\hline Sinus tracts & $07(11.3 \%)$ \\
\hline Fissures & $05(8.0 \%)$ \\
\hline Skin tags & $14(22.6 \%)$ \\
\hline Ulcers & $11(17.7 \%)$ \\
\hline Superficial cutaneous tracts & $05(8.0 \%)$ \\
\hline Anal strictures & $09(14.5 \%)$ \\
\hline Abscesses & $09(14.5 \%)$ \\
\hline Fournier Gangrene & $01(1.6 \%)$ \\
\hline Others* & $14(22.6 \%)$ \\
\hline Performed procedures & \\
\hline Seton placement & $43(69.4 \%)$ \\
\hline Fistulotomy & $14(22.6 \%)$ \\
\hline Skin tag removal & $9(14.5 \%)$ \\
\hline Resection of superficial cutaneous tracts & $4(6.5 \%)$ \\
\hline Stricture dilation & $8(12.9 \%)$ \\
\hline Partial vulvectomy due to Fournier Gangrene & $1(1.6 \%)$ \\
\hline Drainage of abscesses & $9(14.5 \%)$ \\
\hline Resection of external holes with curettage & $14(22.6 \%)$ \\
\hline Ulcer curettage and cauterization & $5(8.0 \%)$ \\
\hline Others** & $12(19.4 \%)$ \\
\hline
\end{tabular}

*Hypertrophied anal papillae, polyps and warts.

${ }^{* *}$ Wart resection and cauterization, local infiltration of corticosteroids, resection of polyps and hypertrophied anal papillae.

in $69.3 \%$ of EUAs, as pictured in - Figure 2(A-B). In specific cases, with simple, short and superficial fistulas, fistulotomy with curettage was performed (22.5\%).

In most EUAs (71\%), the patients were hospitalized for the procedure. In these exams, $51.6 \%$ of the patients used antibiotics, and ciprofloxacin and metronizadole were the most used in $37 \%$ of the cases; $61.3 \%$ were discharged from the hospital within 24 hours, and $29 \%$ had already been hospitalized to be monitored at the gastroenterology clinic or pediatrics.

We compared patients operated in public (HUPES) and private (HBA) hospitals in relation to demographic characteristics and intraoperative findings and procedures performed, and found that the time from the diagnosis of CD until EUA ( $p=0.011)$, the use of biological therapy $(p=0.003)$, and the frequency of rectovaginal fistulas $(p=0.029)$ were higher in patients from the private hospital (-Table 3 ).

\section{Discussion}

Crohn's disease is an inflammatory bowel disease known for skip lesions that affect any part of the gastrointestinal tract, from the mouth to the anus. The mean age at diagnosis has 2 peaks, the first between 20 and 30 years old, and the second 

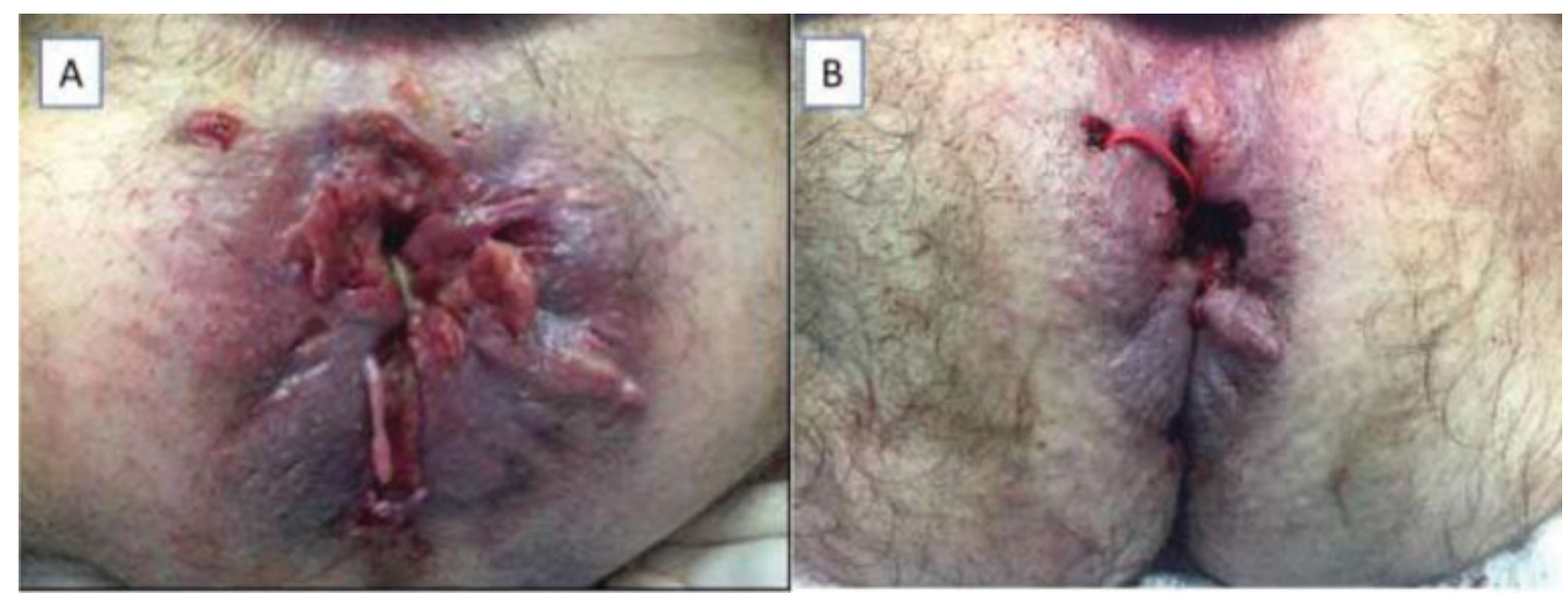

Fig. 2 (A) Perianal Crohn's disease with complex fistula, ulcerations and skin tags; (B) Seton placement in complex anal fistula after anorectal EUA.

Table 3 Univariate comparing of patients from public and private medical centers

\begin{tabular}{|c|c|c|c|c|}
\hline \multicolumn{5}{|c|}{ Analysis of demographic data } \\
\hline \multirow[t]{2}{*}{ Data } & \multirow[t]{2}{*}{ Categories } & $\begin{array}{l}\text { HUPES } \\
(n=36)\end{array}$ & $\begin{array}{l}\text { HBA } \\
(n=10)\end{array}$ & \multirow[t]{2}{*}{ p-value } \\
\hline & & n (\%) & n (\%) & \\
\hline \multirow[t]{2}{*}{ Gender } & Female & $17(47.2)$ & $7(70.0)$ & \multirow[t]{2}{*}{0.289} \\
\hline & Male & 19 (52.8) & $3(30.0)$ & \\
\hline Age & (years old) & $33(25-46)$ & $38(30-60)$ & 0.141 \\
\hline $\begin{array}{l}\text { Diagnosis } \\
\text { DC to EUA }\end{array}$ & (years) & $2(0-6)$ & $12(1-19)$ & 0.011 \\
\hline \multirow{2}{*}{$\begin{array}{l}\text { Number of } \\
\text { EUAs }\end{array}$} & 1 EUA & $30(83.3)$ & $7(70.0)$ & \multirow[t]{2}{*}{0.384} \\
\hline & $>1 \mathrm{EUA}$ & $6(16.7)$ & $3(30.0)$ & \\
\hline \multirow{2}{*}{$\begin{array}{l}\text { Use of } \\
\text { biological } \\
\text { therapy }\end{array}$} & Yes & $4(11.1)$ & $6(60.0)$ & \multirow[t]{2}{*}{0.003} \\
\hline & No & $32(88.9)$ & $4(40.0)$ & \\
\hline \multirow{2}{*}{$\begin{array}{l}\text { Previous } \\
\text { surgery }\end{array}$} & Yes & $9(25.0)$ & $6(60.0)$ & \multirow[t]{2}{*}{0.057} \\
\hline & No & $27(75.0)$ & $4(40.0)$ & \\
\hline \multicolumn{5}{|c|}{ Intraoperative findings and procedures } \\
\hline \multirow[t]{2}{*}{ Data } & \multirow[t]{2}{*}{ Categories } & $\begin{array}{l}\text { HUPES } \\
(n=46)\end{array}$ & $\begin{array}{l}\text { HBA } \\
(n=16)\end{array}$ & \multirow[t]{2}{*}{$p$-value } \\
\hline & & n (\%) & n (\%) & \\
\hline \multirow{2}{*}{$\begin{array}{l}\text { Anorectal } \\
\text { fistula }\end{array}$} & Yes & $39(84.8)$ & $13(81.3)$ & \multirow[t]{2}{*}{0.709} \\
\hline & No & $7(15.2)$ & $3(18.8)$ & \\
\hline \multirow[t]{2}{*}{ Simple } & Yes & $7(15.2)$ & $4(25.0)$ & \multirow[t]{2}{*}{0.378} \\
\hline & No & $39(84.8)$ & $12(75.0)$ & \\
\hline \multirow[t]{2}{*}{ Complex } & Yes & $32(69.6)$ & $9(56.3)$ & \multirow[t]{2}{*}{0.369} \\
\hline & No & $14(30.4)$ & $7(43.8)$ & \\
\hline \multirow{2}{*}{$\begin{array}{l}\text { Rectovaginal } \\
\text { fistula }\end{array}$} & Yes & $6(13.0)$ & $7(43.8)$ & \multirow[t]{2}{*}{0.029} \\
\hline & No & $40(87.0)$ & $9(56.3)$ & \\
\hline \multirow{2}{*}{$\begin{array}{l}\text { Seton } \\
\text { placement }\end{array}$} & Yes & $32(69.6)$ & $11(68.8)$ & \multirow[t]{2}{*}{0.999} \\
\hline & No & $14(30.4)$ & $5(31.3)$ & \\
\hline \multirow[t]{2}{*}{ Fistulotomy } & Yes & $9(19.6)$ & $5(31.3)$ & \multirow[t]{2}{*}{0.488} \\
\hline & No & $37(80.4)$ & $11(68.8)$ & \\
\hline
\end{tabular}

Abbreviations: HBA, Hospital da Universidade Federal da Bahia; HUPES, Hospital Universitário Professor Edgard Santos.

Patient data are numbers and, within parentheses, percentages (\%) or median and interquartile range, in the case of the variables Age and Diagnosis DC to EUA.

Patient data are numbers and, within parentheses, percentages (\%). $\sim 50$ years old. ${ }^{10}$ Our paper shows a profile of young patients with a mean age of 30 years old, which is in line with the literature.

The main segment affected in $\mathrm{CD}$ is the ileocolic, afflicting $\sim 50 \%$ of the patients, whereas for $30 \%$ of the patients it affects the ileum/small bowel only, and for $20 \%$ the colon alone. ${ }^{11}$ However, in perianal $\mathrm{CD}$, fistulas are most frequent in colon compromise, primarily with rectal involvement, occurring singly in between 10 to $15 \%$ of the patients. ${ }^{8}$

Hellers et al. cite that the cumulative frequency of perianal fistulas is of $\sim 92 \%$ in colonic disease patients with rectal involvement, of $41 \%$ in colonic disease patients without rectal involvement, of $15 \%$ with ileocolic involvement, and of $12 \%$ with ileal compromise. ${ }^{12}$ Our case study demonstrates that $56.5 \%$ of the perianal disease patients presented colon and rectum compromise.

The pathogenesis of $C D$ is still unknown, but several genetic and environmental factors seem to increase the risk and lead to an aberrant intestinal immune response. One of its main risk factors is smoking, which doubles the risk of developing the disease. ${ }^{13}$ Smoking is related to more severe forms of the disease, such as penetrating, stenosing, and fistulizing perianal presentations. It is more associated with ileal disease and less often with colonic involvement. ${ }^{14}$ Our study shows a low prevalence of smokers, which probably owes to the fact that the city of Salvador presents one of the lowest smoking rates in Brazil (Vigitel Brasil, 2018 - Ministry of Health). ${ }^{15}$

Crohn's disease is associated with extraintestinal manifestations that can affect the skin, joints, eyes, liver, blood vessels, and kidneys, with arthritis of both the axial and peripheral skeleton as the most common manifestation.

Skin lesions (erythema nodosum and pyoderma gangrenosum) are frequent, and primary sclerosing cholangitis is also associated with inflammatory bowel diseases, but mainly in ulcerative colitis. The present study shows a similar prevalence among arthritis and cutaneous manifestations, as they are the main extraintestinal manifestations of this group.

Crohn's disease frequently presents perianal fistulas that significantly increase its morbidity and impact quality of life of these patients. A population study conducted in Olmsted, 
Table 4 Comparative findings

\begin{tabular}{|l|l|l|l|l|l|}
\hline Author/Year & Design & Anal Fistula & Complex & Simple & Rectovaginal \\
\hline Current paper 2020 & $\begin{array}{l}\text { Tertiary center retrospective series of } \\
\text { patients submitted to EUA }\end{array}$ & $83.8 \%$ & $78.8 \%$ & $21.2 \%$ & $21 \%$ \\
\hline Eglinton et al. $^{19}$ & Population-based cohort study & $50 \%$ & $72 \%$ & $28 \%$ & $7 \%$ \\
\hline Keighley et al. $^{20}$ & Tertiary center cohort study & $47 \%$ & $23 \%$ & $77 \%$ & $5 \%$ \\
\hline
\end{tabular}

Minnesota (USA) documented a 22\% cumulative risk of developing fistulas in CD patients within 10 years, and $26 \%$ in 20 years after diagnosing the disease. ${ }^{16}$ In $\sim 10 \%$ of the patients, the presence of perianal fistula may be the initial manifestation of $\mathrm{CD}$, and in $\sim 5 \%$, it may be the only manifestation of $\mathrm{CD} .{ }^{17}$

Complex fistulas have been described as the most frequent in $\mathrm{CD} .{ }^{18}$ In a population cohort study, Eglinton et al. found anorectal fistulas in $50 \%$ of $C D$ patients, and $>50 \%$ of these fistulas were classified as complex. ${ }^{19}$ In our study, we found a total of $83.8 \%$ of fistulas in the rectal EUAs performed, of which $78.4 \%$ were complex according to the AGA classification. ${ }^{9}$ These findings show a higher perianal disease severity compared with the population cohort of the previously mentioned study, probably because we are a tertiary center, and this is a case series that involves patients who underwent EUAs (- Table 4).

The EUA plays a significant role in the diagnosis: it allows an accurate assessment of the fistulous pathways in perianal fistulizing $\mathrm{CD}$. The examination also allows therapeutic intervention, such as drainage of the abscess and/or placement of noncutting seton in the fistulous tract to prevent abscess formation. ${ }^{5,21}$

The gold standard for treating patients with this form of the disease has been biological therapy combined with surgical treatment, and one of the main drugs used is IFX. Present et al. published the first clinical trial demonstrating the efficacy of IFX to treat perianal fistulas, with 55\% cicatrization in patients treated with IFX $5 \mathrm{mg} / \mathrm{kg}$ compared with $13 \%$ of the placebo group $(p=0.001) .^{22}$ Sands et al. ${ }^{23}$ reinforce that IFX maintenance therapy is superior to placebo for treating anorectal fistulas after the $54^{\text {th }}$ week of study.

During treatment, the skin healing around the external orifice and the closing of the fistula tract in its proximal portions may be associated with an increased risk of abscess formation and recurrence of fistulas. ${ }^{5,23}$ Studies show that performing the EUA before IFX use results in a better initial response and less recurrence when compared to IFX use alone. ${ }^{21}$ Most of the patients (59.6\%) in our sample underwent EUA before using the immunobiological agent to optimize the treatment for perianal fistulizing $\mathrm{CD}$ control.

As mentioned in the results, the use of biological therapy $(p=0.003)$ and the time from the diagnosis of CD until the EUA $(p=0.011)$ were lower in public hospital patients. This can be explained by the more difficult access to high-cost medications (biological therapy) and to the greater severity of patients in the public sector due to late access to the health system due to the long waiting time requiring an EUA earlier.
On the other hand, the higher frequency of rectovaginal fistulas $(p=0.029)$ found in the EUAs performed in the private hospital may reflect the higher rate of female patients in this group (70\% in the Hospital da Bahia group versus $47.2 \%$ in the HUPES group).

The therapeutic approach may vary depending on the type of fistula. Experienced coloproctologists report an accuracy $>90 \%$ in the detection and classification of perianal fistulas, sinuses and abscesses during EUA. ${ }^{6}$

Fistulotomy is a safe treatment option for selected superficial fistulas that present symptoms. Fistulotomy on low fistulas must be a careful decision, especially in women, due to the increased risk of incontinence. The main treatment carried out here was seton positioning, which represents $69.4 \%$ of the interventions. In selected cases, fistulotomy with curettage (22.6\%) was chosen.

Regarding the seton implant - whose importance in the perianal CD management was previously mentioned -, there is still no consensus on the best time to remove nor other strategies concerning a definitive way for treating a fistulous tract. Some of the valid options are myomucosal advancement flap, plugs, fibrin glue, ligation of intersphincteric fistula tract (LIFT), video-Assisted anal fistula treatment (VAAFT), and stem cell therapy. ${ }^{17}$ Setons should only be removed in the absence of proctitis, with a $50 \%$ approximate rate of fistula healing after immunobiological treatment combined with EUA. ${ }^{24}$

The present study has some limitations. The relatively low number of patients and the retrospective design of the study are drawbacks. The data were not from a probabilistic sample. This unique series of highly selected patients with CD submitted to the EUA probably does not represent population studies regarding intraoperative findings and the frequency and type of anal fistulas.

\section{Conclusion}

Crohn's disease frequently presents perianal involvement, with the appearance of abscesses and anorectal fistulas. For these patients, anorectal EUA is necessary due to its diagnostic and therapeutic role, allowing an accurate assessment of the fistulous tract. The performance of EUA before immunobiological therapy is associated with a better clinical response and with higher rates of fistula remission. Therefore, several authors consider that the performance of EUA with biological therapy is the gold standard in perianal fistulizing $C D$. In the present paper, the epidemiological profile, the EUA findings (high incidence of complex anorectal fistulas), and performed 
treatments were consistent with the pattern described in the literature. Additional studies are necessary for a better understanding and management of this unique and debilitating form of the disease.

\section{Conflict of Interests}

The authors have no conflict of interests to declare.

\section{Referências}

1 Jacobsen BA, Fallingborg J, Rasmussen $\mathrm{HH}$, et al. Increase in incidence and prevalence of inflammatory bowel disease in northern Denmark: a population-based study, 1978-2002. Eur J Gastroenterol Hepatol 2006;18(06):601-606

$2 \mathrm{Ng} \mathrm{SC}$, Shi HY, Hamidi N, et al. Worldwide incidence and prevalence of inflammatory bowel disease in the 21st century: a systematic review of population-based studies. Lancet 2017; 390(10114):2769-2778

3 Penner A, Crohn BB. Perianal fistulae as a complication of regional ileitis. Ann Surg 1938;108(05):867-873

4 Lewis RT, Bleier JI. Surgical treatment of anorectal Crohn's disease. Clin Colon Rectal Surg 2013;26(02):90-99

5 Regueiro M, Mardini H. Treatment of perianal fistulizing Crohn's disease with infliximab alone or as an adjunct to exam under anesthesia with seton placement. Inflamm Bowel Dis 2003;9(02):98-103

6 Schwartz DA, Wiersema MJ, Dudiak KM, et al. A comparison of endoscopic ultrasound, magnetic resonance imaging, and exam under anesthesia for evaluation of Crohn's perianal fistulas. Gastroenterology 2001;121(05):1064-1072

7 Hyder SA, Travis SP, Jewell DP, McC Mortensen NJ, George BD. Fistulating anal Crohn's disease: results of combined surgical and infliximab treatment. Dis Colon Rectum 2006;49(12):1837-1841

8 Cellini C, Safar B, Fleshman J. Surgical management of pyogenic complications of Crohn's disease. Inflamm Bowel Dis 2010;16 (03):512-517

9 Sandborn WJ, Fazio VW, Feagan BG, Hanauer SBAmerican Gastroenterological Association Clinical Practice Committee. AGA technical review on perianal Crohn's disease. Gastroenterology 2003; 125(05):1508-1530

10 Feuerstein JD, Cheifetz AS. Crohn's Disease: Epidemiology, Diagnosis, and Management. Mayo Clin Proc 2017;92(07):1088-1103

11 Cheifetz AS. Management of active Crohn's disease. JAMA 2013; 309(20):2150-2158

12 Hellers G, Bergstrand O, Ewerth S, Holmström B. Occurrence and outcome after primary treatment of anal fistulae in Crohn's disease. Gut 1980;21(06):525-527
13 Mahid SS, Minor KS, Soto RE, Hornung CA, Galandiuk S. Smoking and inflammatory bowel disease: a meta-analysis. Mayo Clin Proc 2006;81(11):1462-1471

14 Lakatos PL, Czegledi Z, Szamosi T, et al. Perianal disease, small bowel disease, smoking, prior steroid or early azathioprine/ biological therapy are predictors of disease behavior change in patients with Crohn's disease. World J Gastroenterol 2009;15 (28):3504-3510

15 Brasil Ministério da Saúde. Secretaria de Vigilância em Saúde. Vigitel Brasil, 2018: Vigilância de Fatores de Risco e Proteção para Doenças Crônicas por Inquérito TelefônicoBrasília: Ministério da Saúde; 2019

16 Schwartz DA, Loftus EV Jr, Tremaine WJ, et al. The natural history of fistulizing Crohn's disease in Olmsted County, Minnesota. Gastroenterology 2002;122(04):875-880

17 Kotze PG, Shen B, Lightner A, et al. Modern management of perianal fistulas in Crohn's disease: future directions. Gut 2018;67(06):1181-1194

18 Bell SJ, Williams AB, Wiesel P, Wilkinson K, Cohen RCG, Kamm MA. The clinical course of fistulating Crohn's disease. Aliment Pharmacol Ther 2003;17(09):1145-1151

19 Eglinton TW, Barclay ML, Gearry RB, Frizelle FA. The spectrum of perianal Crohn's disease in a population-based cohort. Dis Colon Rectum 2012;55(07):773-777

20 Keighley MRB, Allan RN. Current status and influence of operation on perianal Crohn's disease. Int J Colorectal Dis 1986;1(02):104-107

21 Schwartz DA, Ghazi LJ, Regueiro M, et al;Crohn's \& Colitis Foundation of America, Inc. Guidelines for the multidisciplinary management of Crohn's perianal fistulas: summary statement. Inflamm Bowel Dis 2015;21(04):723-730

22 Present DH, Rutgeerts P, Targan S, et al. Infliximab for the treatment of fistulas in patients with Crohn's disease. N Engl J Med 1999;340 (18):1398-1405

23 Gecse KB, Bemelman W, Kamm MA, et al;World Gastroenterology Organization, International Organisation for Inflammatory Bowel Diseases IOIBD, European Society of Coloproctology and Robarts Clinical Trials World Gastroenterology Organization International Organisation for Inflammatory Bowel Diseases IOIBD European Society of Coloproctology and Robarts Clinical Trials. A global consensus on the classification, diagnosis and multidisciplinary treatment of perianal fistulising Crohn's disease. Gut 2014;63 (09):1381-1392

24 Kotze PG, Albuquerque IC, da Luz Moreira A, Tonini WB, Olandoski $\mathrm{M}$, Coy CSR. Perianal complete remission with combined therapy (seton placement and anti-TNF agents) in Crohn's disease: a Brazilian multicenter observational study. Arq Gastroenterol 2014;51(04):284-289 